\title{
Head and Neck Cancer pN2a TNM Finding v8
}

National Cancer Institute

\section{Source}

National Cancer Institute. Head and Neck Cancer pN2a TNM Finding v8. NCI Thesaurus. Code C132648.

Head and neck cancer with metastasis in a single ipsilateral lymph node $3 \mathrm{~cm}$ or smaller in greatest dimension and $\mathrm{ENE}(+)$; or metastasis in a single ipsilateral lymph node larger than $3 \mathrm{~cm}$ but not larger than $6 \mathrm{~cm}$ in greatest dimension and ENE(-). (from AJCC 8th Ed.) 